\title{
What Drives the Climate: Man or Nature?
}

Pavel Tarasov $^{1}$, Victor Brovkin ${ }^{2}$ and Mayke WagneR ${ }^{3}$

'Department of Earth Sciences, Free University of Berlin, 12249 Berlin, Germany; ptarasov@zedat.fu-berlin.de ${ }^{2}$ Climate System Department, Potsdam Institute for Climate Impact Research, 14412, Potsdam, Germany; victor@pik-potsdam.de ${ }^{3}$ Eurasia Department, German Archaeological Institute, 14195 Berlin, Germany; mw@eurasien.dainst.de

Traditionally, human-environment interactions are discussed in terms of the influence of climatic changes and catastrophes on civilizations (Battarbee et al., 2004; Yasuda and Shinde, 2004). Recently, a hypothesis suggesting the onset of the "anthropogenic greenhouse era" about $8 \mathrm{ka}$ ago as a result of forest clearance and agriculture was proposed to explain the pre-industrial rise in $\mathrm{CO}_{2}$ and $\mathrm{CH}_{4}$ concentrations (Ruddiman, 2003; see also PAGES News 2004/1). Consequently, man was deemed the "rescuer" of the Earth from a new Ice Age, otherwise predicted at about 4 ka ago. Opponents of this hypothesis argued that natural forces were responsible for the pre-industrial increase in greenhouse gases (Broecker and Clark, 2003, Joos et al., 2004).

These contradictory views and the current discussion they have provoked (Claussen et al. 2005; Crucifix et al. 2005; Ruddiman, 2005; Broecker and Stocker, 2005) are far more than a scholastic debate with only theoretical value. We regard integrative palynological and archeological studies in combination with modeling as a promising path towards a better understanding of the mechanisms and forces driving the Holocene climate. This understanding is crucial for reliable projections of climate in the future.

\section{Palynological and Archeological Records}

Except for desert areas, arboreal pollen $(A P)$ percentages represent well the tree-cover around the sampling site. Figure 1 presents pollenbased cases of the Holocene forest dynamics from several regions with a strong anthropogenic impact on vegetation.

\section{Case 1: Easter Island}

Figure 1a shows changes in AP percentages on Easter Island, settled by people about 1,600 years ago (Kirch, 2000). Flenley (2001) suggested the

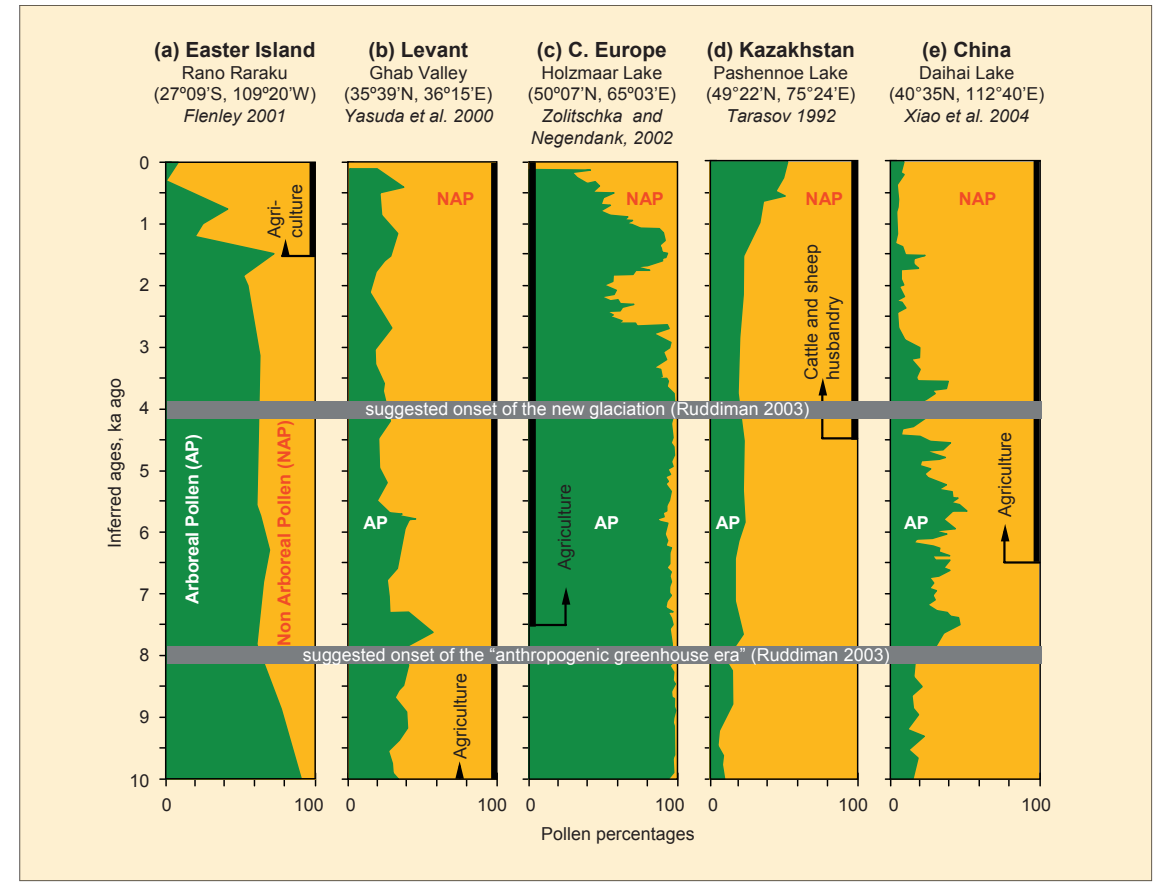

Fig. 1: Changes in arboreal (AP) and non-arboreal (NAP) pollen percentages since $10 \mathrm{ka}$ ago and the occurrence of agriculture (a-c,e) or cattle and sheep husbandry (d).

island-originally covered with palm forest-was completely deforested during the subsequent thousand years. A distinct decrease in AP from $90 \%$ at $10 \mathrm{ka}$ to $55 \%$ at $2 \mathrm{ka}$ implies a "deforestation" that is not related to human activity, long-distance pollen transport or species competition (Flenley, 2001) and requires an alternate explanation. Rolett and Diamond (2004) suggested that even Easter Island's eventual forest extinction "was not because its people were especially improvident but because they faced one of the Pacific's most fragile environments."

\section{Case 2: The Levant}

Large-scale man-made deforestation can be assumed in Syria accompanying the inception of agriculture (Zohary and Hopf, 2000). In the Ghab record (Fig. 1b) AP varied from $55 \%$ to $30 \%$ during $10 \mathrm{ka}$ to $5.6 \mathrm{ka}$, and from $25 \%$ to $15 \%$ during the later period. Yasuda (2001) reported that a decrease in pollen percentages for deciduous oak at $10 \mathrm{ka}$ was accompanied by an increase in evergreen oak and olive pollen percentages and by high frequencies for charcoal particles. The Ghab record illustrates anthropogenic deforestation but the Hula record from Israel (Baruch and Bottema, 1999) fails to reproduce the same story-a reminder that any spatial extrapolation of deforestation requires careful investigation, including modeling of climatesensitive taxa/biome distributions.

\section{Case 3: Central \& Northern Europe} In mid-latitude Europe, noticeable changes in AP exceeding natural variability occurred after 3 ka ago (Berglund, 1991; Zolitschka and Negendank, 2002: Fig. 1c), i.e. 4.5 ka after central Europe and $3 \mathrm{ka}$ after northern Europe acquired agriculture (Rowley-Conwy, 2004). To link plant cultivation with deforestation poses the challenge of confronting pollen with archeological data following the spread of agriculture from the Levant across Europe. Nevertheless, the forest decline about $3 \mathrm{ka}$ ago coincides with the Late Bronze Age intensification of landuse (Berglund 2003).

\section{Case 4: Kazakhstan}

By contrast to cases 1 to 3, pollen records from Kazakhstan (Tarasov, 


\section{Science Highlights}

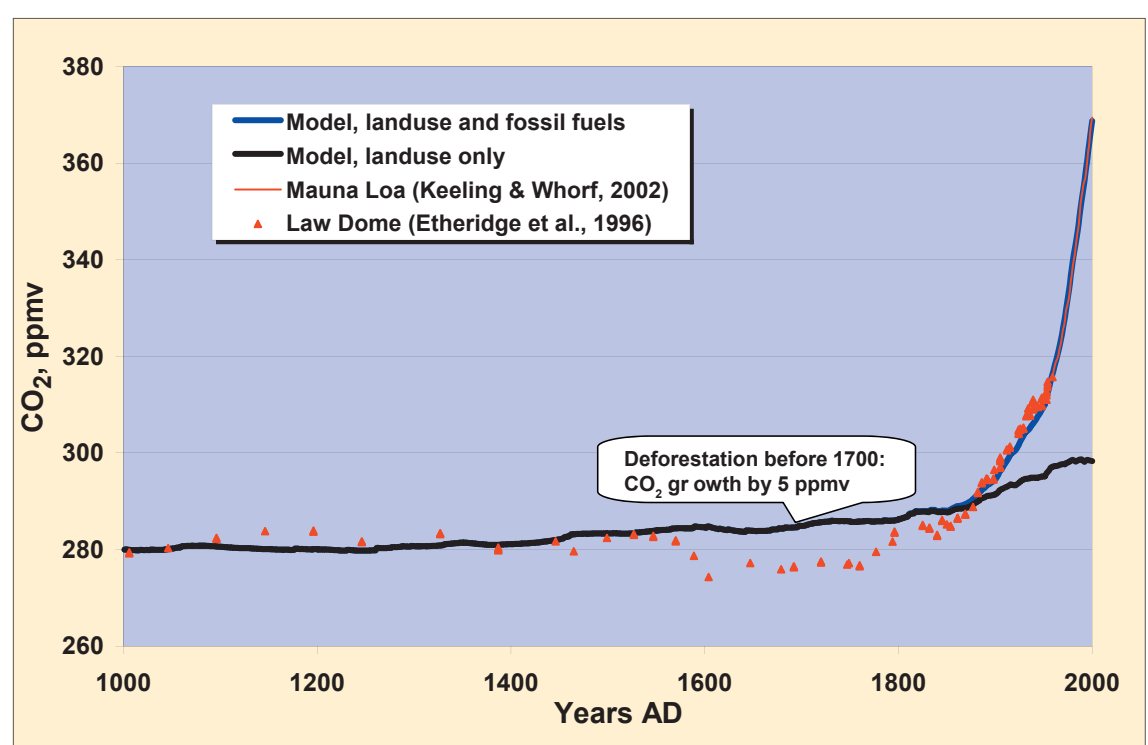

Fig. 2: Atmospheric $\mathrm{CO}_{2}$ concentration from the CLIMBER-2 simulations for the last millennium driven by changes in landuse (Ramankutty and Foley, 1999), black line, and by changes in landuse plus fossil fuel emissions (Marland et al., 2002), blue line; for details see Brovkin et al. (2004).

1992; Kremenetski et al., 1997) offer a different scenario of forest dynamics, suggesting that forestation of the steppe zone started at 6 ka and reached a maximum during the last millennium (Fig. 1d). Until the mid-Holocene, tree cover was minimal and did not experience any traceable impact of pastoralism or agriculture (Rosen et al., 2000). The remaining question is: to what extent were other parts of the Eurasian steppes free from forest clearance and did not influence the pre-industrial $\mathrm{CO}_{2}$ rise?

\section{Case 5: China}

Forest dynamics on the Chinese landmass undoubtedly influenced the Holocene climate. At about 8 ka ago, Neolithic people subsisted mainly on cultivated millet in the northern plains (Chang, 1986) and on rice in the south (Crawford and Shen, 1998). The 2 ka time-slice saw the expansion of the Han Empire, bordered by local kingdoms in the south and the mighty confederation of Xiongnu tribes in the north. The tasks ahead of us include quantitative evaluation of settlement/population density and forest clearance; and explanations for high AP percentages in central Inner Mongolia (Fig. 1e) during early intensive settlement development (Tian, 1991a, 1991b) and for a major expansion of trees in south-eastern China at 6 or $4 \mathrm{ka}$ (Ren and Beug, 2002), when the number of settlements drastically increased (Zhang, 2000).

\section{Mapping of Holocene Forest Dynamics}

Quantitative approaches facilitate the transformation of pollen records into vegetation maps (Sugita, 1993) as demonstrated by the successful reconstruction of forest and cultural landscape dynamics in southern Sweden (Berglund, 1991; Gaillard et al., 1994; Sugita et al., 1999). Surface pollen and remote sensing based vegetation datasets matched by a modern analogue technique were applied to fossil pollen records from North America (Williams, 2003) in order to map post-glacial tree-cover changes. This approach was successfully tested with data from Eurasia (Brewer et al., 2005) and can be applied on a global scale.

\section{Modeling: Climate, Vegetation, Carbon Cycle}

Previous estimates of pre-industrial emissions associated with anthropogenic land-use are limited to 60-80 $\mathrm{PgC}$ (House et al., 2002) which corin atmospheric $\mathrm{CO}_{2}$ concentration (Brovkin et al. 2004, Fig. 2). However, this is a very preliminary estimate because a global-scale dataset on the timing and magnitude of anthropogenic deforestation prior to 1700 AD is not available. Since most responds to a 3-5 ppmv increase changes in the carbon balance are associated with changes in tree cover, its global reconstruction provides a firm constraint on the land carbon balance. We suggest combining the potency of terrestrial biogeochemistry models with pollen-based reconstruction of tree cover to evaluate changes in land carbon storage, either in transient simulations or in frequent time-slice experiments. Interactive climate-vegetation simulations performed by several models can be used to evaluate the uncertainty in climate changes.

\section{Call for a New Initiative}

IGBP-PAGES BIOME 6000 Project (Prentice and Webb, 1998) involved many individuals and research groups all over the world in pollen data synthesis and quantitative reconstruction of the mid-Holocene and LGM biomes. Furthermore, it initiated close co-operation between pollen and modeling communities and produced substantial new results. Extending on BIOME 6000 and adding to ongoing Focus 5 activities on human-environment interactions, we suggest to launch a new international initiative addressing the Man-Trees-Climate System (MATRICS) that will bring together paleobotanical and archeological records with modeling results and set direct evidence of human activities against indirect signs of human impact on vegetation.

\section{REFERENCES}

Berglund, B.E. 2003: Human impact and climate changes - synchronous events and a causal link? Quaternary International, 105: 7-12.

Claussen, M., Brovkin, V., Calov, R., Ganopolski, A. and Kubatzki, C., 2005: Did humankind prevent an early glaciation? Comment on Ruddiman's hypothesis of a pre-historic anthropocene. Climatic Change, 69: 409-417.

Ruddiman, W.F., 2003: The anthropogenic greenhouse era began thousands of years ago. Climatic Change, 61: 261-293.

Williams, J.W., 2003: Variations in tree cover in North America since the last glacial maximum. Global and Planetary Change, 35: 1-23.

Yasuda, Y., Kitagawa, H. and Nakagawa, T., 2000: The Earliest Record of Major Anthropogenic Deforestation in Ghab Valley, North-west Syria: A Palynological Study. Quaternary International 73/74: 127-136

For full references please consult: www.pages-igbp.org/products/newsletters/ref2005_2.htm 